\title{
The diet of greater crested terns off southeast Australia varies with breeding stage and sea surface temperature
}

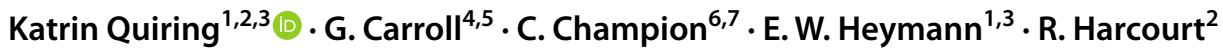

Received: 31 January 2021 / Accepted: 21 July 2021 / Published online: 18 August 2021

(c) The Author(s) 2021

\begin{abstract}
Monitoring seabird diet can provide insights into marine ecosystems that are logistically difficult or costly to observe with traditional fisheries survey methods. Using digital photography, we described the diet of greater crested terns (Thalasseus bergii) breeding on Montague Island ( $\left.36^{\circ} 15^{\prime} \mathrm{S}, 150^{\circ} 13^{\prime} \mathrm{E}\right)$, a colony located in an oceanographically dynamic region of southeast Australia. We investigated how the type and size of prey brought back to the colony changed in relation to both breeding stage and variation in local environmental conditions. 2469 prey items were identified to species or family level over 35 consecutive days of photo-sampling in 2018. Australian anchovy (Engraulis australis), a surface-schooling clupeid fish, was the most abundant prey returned to the colony during all breeding stages $(84.5 \%)$. The proportion of anchovy increased from $77.0 \%$ when birds were provisioning their adult partners during incubation, to $92.4 \%$ when they were provisioning chicks, suggesting selective foraging behaviour on this energy-rich species to facilitate rapid chick growth. Anchovy size was significantly larger during incubation $(91.1 \pm 14.9 \mathrm{~mm})$, smaller during early chick provisioning $(71.8 \pm 11.0 \mathrm{~mm})$, and increased slightly during mid provisioning $(79.6 \pm 11.9 \mathrm{~mm})$, indicating adaptive prey selection that is matched to the physical requirements of different breeding stages. The proportion of anchovy prey was also influenced by sea surface temperature (SST), with anchovy becoming more dominant with increasing local SSTs, up to $\sim 17.5^{\circ} \mathrm{C}$. This study gives new insight into the types of prey that are seasonally available to predators in this region. The strong specialisation by greater crested terns for one energy-rich species of schooling fish (anchovy) suggests that variation in the size and composition of their prey may serve as an indicator of change in the pelagic ecosystem off southeast Australia.
\end{abstract}

Responsible Editor: V. Paiva.

Reviewed by: undisclosed experts.

Katrin Quiring

katrin.quiring@students.mq.edu.au

1 Department of Sociobiology/Anthropology, Georg-AugustUniversity, Göttingen, Germany

2 Department of Biological Sciences, Macquarie University, Sydney, NSW 2109, Australia

3 Verhaltensökologie \& Soziobiologie, Deutsches Primatenzentrum, Leibniz Institut für Primatenforschung, Göttingen, Germany

4 School of Aquatic and Fisheries Sciences, University of Washington, Seattle, USA

5 Environmental Defense Fund, Seattle, USA

6 Fisheries Research, NSW Department of Primary Industries, Coffs Harbour, NSW, Australia

7 National Marine Science Centre, Southern Cross University, Coffs Harbour, NSW, Australia

\section{Introduction}

Upper trophic-level predators such as seabirds can act as sentinels of changes in marine ecosystems, with their demography, behaviour and physiology reflecting variability in oceanographic and ecological conditions (Hazen et al. 2019). For example, temporal changes in the occurrence, abundance and size of prey that seabirds consume can be used as indicators of food availability and ecosystem structure (Suryan et al. 2002; Parsons et al. 2008), and can provide an early warning of anthropogenic impacts on food webs (Green et al. 2015). Monitoring seabird diets can therefore be an important tool to inform conservation biology and ecosystem-based fisheries management (e.g. Lorentsen et al. 2018; Thayne et al. 2019; Hazen et al. 2019).

During the breeding season, the foraging range of seabirds is constrained by central-place foraging, which requires individuals to return to the colony between foraging trips to incubate eggs or provision their young (Cairns 1988). Optimal foraging theory for central-place foraging 
predicts that single-prey loaders (species including guillemots and terns that carry a single whole prey item per foraging trip back to the colony) should maximise the energy load per unit foraging by providing large, or energetically rich prey items to their chick (Orians and Pearson 1979; Pichegru et al. 2007). This behaviour is assumed to be adjusted to energetic requirements and ingestion capabilities of developing juveniles, with parents selecting increasingly larger fish as the chick grows, to optimise the energy gained by offspring during each feeding event (Batchelor and Ross 1984). This means that birds must forage efficiently within a relatively short distance of the colony, to select high-quality prey items.

While intrinsic constraints imposed by provisioning requirements may influence prey selection during breeding, the availability of prey also varies with extrinsic environmental conditions. Temporal variation in oceanographic conditions can have a strong effect on the foraging success of seabirds, which can impact their body condition, growth and ultimately reproductive performance (Harwood et al. 2015). This is particularly true during the breeding season when birds are restricted to finding prey within a limited distance from the colony and cannot move to more favourable foraging areas. Local prey distribution and abundance can be strongly affected by variables at seasonal timescales, including phenological changes in sea surface temperature (SST). Seasonal changes in SSTs affect the spatial distribution and abundance of small pelagic fishes, which are an important food source for many seabird species (Hansen et al. 2001; Peck et al. 2021). In Norway, for example, sea temperature controls plankton production, which in turn influences the abundance of the Atlantic puffin's (Fratercula arctica) main prey, first-year herring, mediating fledgling success in this population (Durant et al. 2003).

Seabird prey availability also varies at short (i.e. daily) time scales (White 2008) in response to, for example, weather events. Prey capture by seabirds under adverse weather conditions can be exacerbated by poor flight performance, or by reductions in prey detectability or catchability (Elliott et al. 2014; Kogure et al. 2016). High wind speeds and wave heights affect the visual capabilities of seabirds due to changes in water turbidity, requiring more abovewater searching for key prey species (Elliott et al. 2009). For example, there is evidence that high wind speeds influence foraging success in seabirds, as indicated by a decrease in the dominant prey captured, as well as a reduction in prey energetic value and size (Stienen et al. 2000; Elliott et al. 2014; Howells et al. 2017). Examining both intrinsic (i.e. physical requirements of chicks vs. adults) and extrinsic (i.e. environmental variability) processes affecting prey capture are crucial for understanding spatiotemporal differences in diet composition.
Here, we used digital photo sampling (Gaglio et al. 2017) as a non-invasive method to study food provisioning of greater crested terns (Thalasseus bergii) at Montague Island, an ecologically important breeding site for seabirds and fur seals in southeast Australia. Montague Island is situated in the path of the strengthening East Australian Current (EAC), in an ocean warming hotspot where SSTs are rising faster than the global average (Wu et al. 2012; Hobday \& Pecl 2014), and faster than elsewhere on the Australian coast (Malan et al. 2021). Understanding the foraging ecology of marine predators breeding in this region and how this is related to local environmental variability will give new insight into the prey species that are seasonally available in this region, and provide a baseline for future studies seeking to understand the effects of climate change on this coastal pelagic ecosystem (Carroll et al. 2016).

We assessed the type and size of single prey items brought back to the colony by terns throughout the breeding season in 2018. We also quantified differences in prey composition between incubation, when terns bring prey back for their partner at shift-change, and chick provisioning at different stages of chick development. We focussed our analyses on the proportion and size of anchovy brought back to the nest, as anchovy was found to be the dominant prey species brought back to this colony, and is an important energy-rich species in the diet of marine top predators in southeast Australia (Hoedt and Dimmlich 1994; Hobday 1992) and crested terns elsewhere (Mcleay et al 2009; Chiaradia et al 2002; Gaglio et al. 2018). Given that anchovy is a locally abundant, lipid-rich prey item, we tested our predictions that (1) the proportion of anchovy in the diet would increase during chick provisioning stages, to facilitate the rapid growth of small chicks (Batchelor and Ross 1984); (2) that anchovy standard length (SL) would decrease between incubation and the early chick provisioning period when offspring are small, then increase during mid provisioning as parents adjust prey size in accord with the ingestion capabilities of growing chicks. We also examined diet composition of greater crested terns in response to short-term variation in environmental variables. We predicted that (3) the proportion of anchovy returned to the colony would decrease under adverse environmental conditions (e.g. strong winds, high waves and anomalously warm SSTs) that influence the availability and/or catchability of surface-schooling prey.

\section{Methods}

\section{Study site and species}

This study was undertaken at Montague Island $\left(36^{\circ} 15^{\prime} \mathrm{S}\right.$, $150^{\circ} 13^{\prime} \mathrm{E}$ ), an 81 ha nature reserve located approximately $9 \mathrm{~km}$ off the coast of southeast New South Wales, Australia. 
Greater crested terns nest in the open on the island at high densities. The tern colony on Montague Island comprises multiple sub-colonies; this study was conducted on the largest and most accessible one, consisting of ca. 1000 breeding pairs in 2018 (Fig. 1a; counted from a wide-angle photograph of the colony taken on 20 October 2018). The study was conducted over 35 consecutive days from 2 October to 5 November during the 2018 greater crested tern breeding season. Similar to other greater crested tern colonies (e.g. Gaglio et al. 2018), chicks hatch synchronously on Montague Island. Therefore, the first chick sighting was selected as the day of hatching and the start of provisioning (23 October 2018- study day 22). Breeding stages were classified as incubation, early provisioning and mid provisioning, and the study covered the full period from incubation to mid provisioning. During incubation, partners alternatively incubate the nest and bring single prey items to their mate when they change shifts. Early provisioning comprised the week following hatching during which both parents provision the chick in the nest scrape (Watson 2012), and mid provisioning the subsequent week when chicks start to leave the nest (Gaglio et al. 2018).

\section{Photographic sampling}

Greater crested tern diet was investigated using digital photography to assess differences between adults and chicks in the size and type of prey consumed over the course of the study period following Gaglio et al (2017). Adult terns carrying prey in their bill were photographed as they returned to the colony (Fig. 1a) using a Canon (Tokyo, Japan) 50D camera fitted with a Canon EF 70-300 mm f/4.0-5.6 IS USM tele zoom lens set to: (1) shutter speed priority 1/2500-1/4000 s depending on light conditions, (2) automatic ISO, (3) high-speed continuous shooting, (4) autofocus on AI servo (autofocus system for continuous tracking of moving subjects), and (5) large Jpeg file format. The tele zoom lens was set to autofocus with the image stabiliser on.

Every day, photos of birds arriving with prey at the colony were taken continuously during three two-hour sessions (morning session from 0700 to $0900 \mathrm{~h}$, midday session from 1100 to $1300 \mathrm{~h}$ and afternoon session from 1500 to $1700 \mathrm{~h}$ AEST; after daylight savings from 0800 to $1000 \mathrm{~h}, 1200$ to $1400 \mathrm{~h}$ and 1600 to $1800 \mathrm{~h}$ AEDT), in sum a sampling effort of $210 \mathrm{~h}$. Photos were taken from a different vantage point during each session to account for sun position. Photos were taken as a photo-set consisting of three images, with the sharpest selected for prey identification and measurements. The distance between the vantage points and the closest bird was approximately $5 \mathrm{~m}$. The birds did not show any sign of stress or disturbance due to the presence of the photographer and sessions were limited to two hours to avoid observer fatigue.

\section{Identification of prey species}

All blurred and unclear images (due to e.g. distance, position of prey in the bill, light conditions and other restrictions) were excluded from the analyses. From the remaining photographs, prey was identified to the highest possible taxonomic resolution (usually to species or family level), based on morphological characteristics (Fig. 1b-k). Fish identification was undertaken by comparing photographs with published images and fish identification guides from the Australian Museum (https://australian.museum/learn/animals/fishes), and subsequently verified by multiple species experts from the NSW Department of Primary Industries and the University of New South Wales, Australia.

\section{Estimation of anchovy size}

Australian anchovy was chosen as a standard by which to compare the size of prey brought back to the colony during different breeding stages using the method detailed by Gaglio et al. (2017). Importantly, Gaglio et al (2017) used the European anchovy (E. encrasicolus) to create length regressions for anchovy eye diameter, head and operculum width. These equations were applied to measurements of Australian anchovy in this study. The morphometric characteristics of both species are very similar, although the European anchovy is slightly larger than the Australian anchovy (average length 13.5 vs. $12 \mathrm{~cm}$; Whitehead et al. 1988). Since this study aimed to compare relative fish length within the sample rather than illustrating variability in absolute fish length, regression equations calculated for European anchovy were used with the caveat that these measurements may consistently bias the true length of Australian anchovy photographed in this study.

\section{Environmental factors}

Key environmental variables that are likely to influence either the distribution or abundance of prey species in the greater crested terns' foraging range, and/or the terns' ability to catch them were selected for analysis. These included wind speed, sea surface temperature (SST) and wave height. Wind speed $(\mathrm{km} / \mathrm{h})$ was recorded by the Australian Bureau of Meteorology weather station (IDN60801) located at the lighthouse on Montague Island (www.bom.gov.au). Wind measurements were made using an automatic anemometer with an accuracy of $\pm 5 \%$ of the wind speed for wind speeds $\geq 10 \mathrm{~m} / \mathrm{s}$. Wind data were recorded as the average of $10 \mathrm{~min}$ bursts at $30 \mathrm{~min}$ intervals.

Gap-free daily records of satellite-derived SST at a $0.05^{\circ} \times 0.05^{\circ}$ spatial resolution were measured by the UK Met Office's Operational Sea Surface Temperature and Ice 


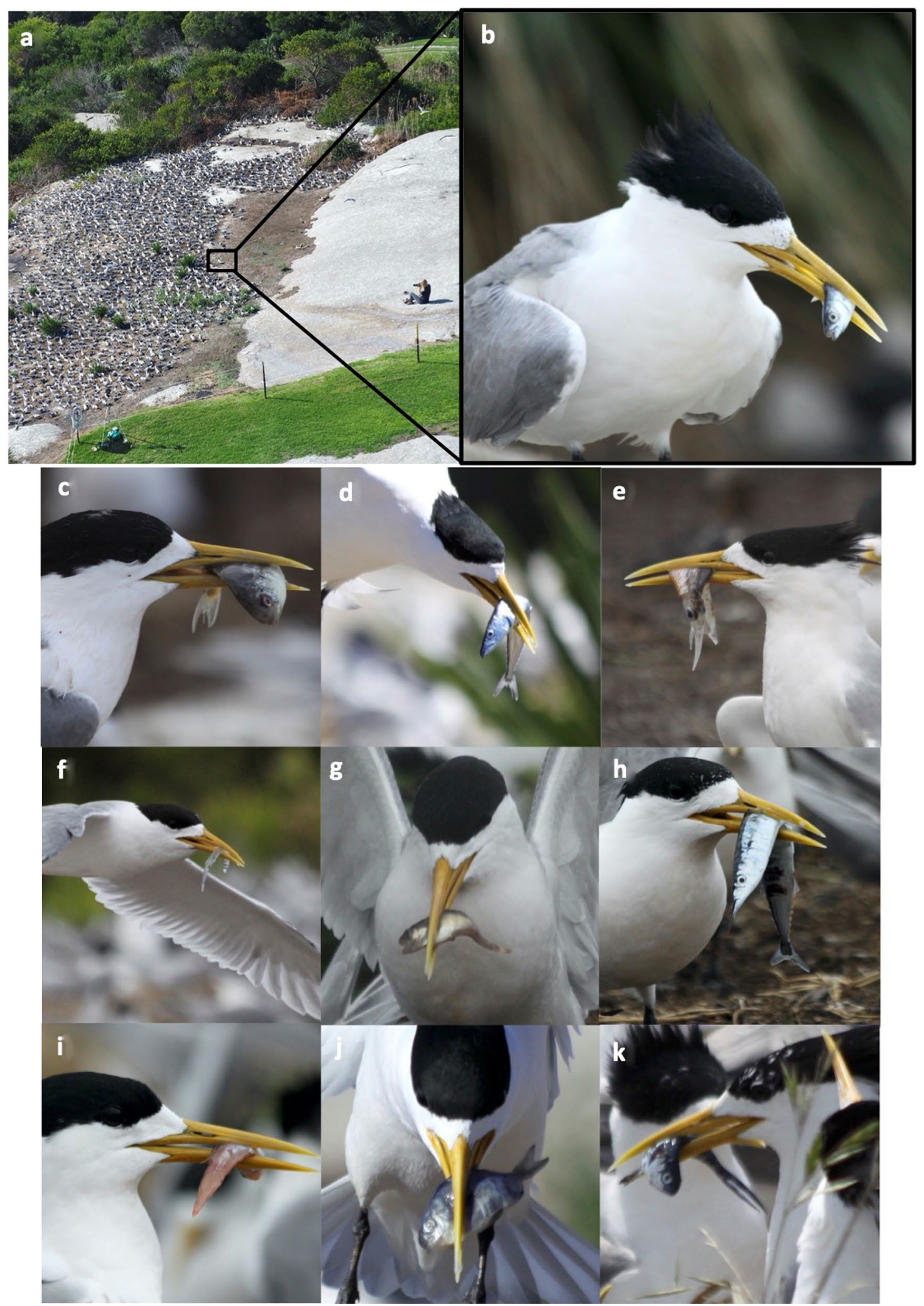


४Fig. 1 a Photo of the greater crested tern colony taken from a lighthouse at Montague Island, New South Wales, showing the photographer at vantage point 1 capturing photo-sets of adult terns carrying single-prey items to the colony at a distance that does not cause disturbance to nesting birds. b The resulting close-up image of the prey used for identification and measurements. Examples of tern prey items: b Australian anchovy, Engraulis australis; c Trevally spp. (juvenile), Centrolophidae spp.; d Barracouta, Thyrsites atun; e Southern calamari squid, Sepioteuthis australis; f Eastern sea garfish, Hyporhamphus australis; g Redbait, Emmelichthys nitidus; h King gar, Scomberesox saurus; i Goatfish spp. (juvenile), Mullidae spp.; j Silver sweep, Scorpis lineolata; k Bluebottle fish, Nomeus gronovii

Analysis (OSTIA) system (downloaded from marine.copernicus.eu). Based on previous observations of the terns' foraging range from Montague Island (O'Hara 2016), SST values were averaged across an area spanning $35^{\circ}$ to $37^{\circ}$ north to south, from the coast out to the edge of the continental shelf (i.e. $200 \mathrm{~m}$ depth isobath). Because SST was available at a daily temporal resolution, daily values were assigned to multiple photography sessions within a day.

Wave height (m) was recorded by the NSW Department of Planning, Industry and Environment's (DPIE) Batemans Bay

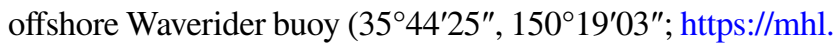
nsw.gov.au/Station-BATBOW; approximately $53 \mathrm{~km}$ north of Montague Island). Data were recorded in bursts (lasting approximately $34 \mathrm{~min}$ long starting on the hour) at 0.5 -s intervals. Wave height for each of these periods is defined as the mean height of the largest $33 \%$ of waves.

Previous GPS tracking work on Montague Island showed that in most years, tern foraging trips last on average 2.2-3.1 h (O'Hara 2016). Hence any photo taken at the colony during a two-hour sampling period could reflect foraging conditions up to two or more hours earlier than the actual sampling time. Therefore, wind and wave data were assigned to a photo session by taking an average of each variable across a four-hour period starting two hours prior to each session.

\section{Data analysis and statistics}

The number of each prey species as a proportion of the total number of prey photographed throughout the study period was calculated to quantify the diet composition of greater crested terns during the 2018 breeding season on Montague Island. Key prey species, i.e. species making up $>1 \%$ of the diet, were identified to simplify graphical illustrations and statistical analyses. The proportion of each prey type was calculated for each two-hour photo session, and compared between breeding stages.

A chi-squared goodness-of-fit test was conducted to assess differences in diet composition between incubation and chick provisioning. A generalised linear mixed model (GLMM) with beta error structure and logit function was used to investigate the effect of breeding stage on the proportion of anchovy returned to the breeding colony by adult terns. Prior to analysis, the response variable (anchovy proportion) was compressed to avoid absolute values of zero or one by taking $y=(y \times(n-1)+0.5) / n$, where $n$ is the sample size (Smithson and Verkuilen 2006). The model was fitted in R using the package 'glmmTMB' (version 1.0.1; Brooks et al. 2017). Similarly, a linear mixed model (LMM; R package 'Ime4'; Bates et al. 2014) was used to investigate the effect of breeding stage on the dependent variable anchovy SL. Each of the models included breeding stage as fixed term and study day ( $N=35$ days) as crossed random effect to account for the repeated three-session per day design. Finally, a post hoc test was performed using the package 'emmeans' (version 1.4.6; Lenth 2020) to investigate the effect within each breeding stage category. Results were Tukey-adjusted for multiple testing. For all analyses, model assumptions were checked following Zuur et al (2009).

To visualise differences in prey composition in relation to breeding stage, a non-metric multidimensional scaling plot (NMDS) was generated using the R package 'vegan' (Oksanen 2011). NMDS is an ordination technique to represent the position of data points in multidimensional space using distance measures and a reduced number of dimensions (typically 2). The Hellinger transformation was applied to remove any tendency for the main prey to be excessively dominant (Borcard et al. 2018). The Bray-Curtis dissimilarity index was used to create a distance matrix that reflects the multidimensional distance between data points with objects grouped closer together being more similar. Ellipses were plotted to depict the centroid and inertia of each breeding stage.

Generalised additive mixed models (GAMMs) using a beta regression and logit function were used to assess the influence of environmental variables (SST, wave height, wind speed) on the proportion of prey species in the diet. GAMMs, as an extension to GLMMs, allow an estimation of potential non-linear relationships between continuous explanatory variables and the response. The models were fitted using the R package 'mgcv' (version 1.8-31; Wood 2006). Smoother terms were applied to explanatory environmental variables and were generated using regression splines. Explanatory variables also included breeding stage as a fixed effect and study day as crossed random effect to account for intraclass correlations among day-specific sampling events. An alpha level of 0.05 was used to determine statistical significance. All statistical analyses were carried out in R (v3.5.3; R Core Team 2017).

\section{Results}

\section{Diet composition}

Over the 35 consecutive days of photo sampling, 3280 photo-sets were taken, yielding images of 2469 prey items 
(76\%) identifiable to species or family level. 1265 prey items were identified during incubation and 1204 items during provisioning (early provisioning: $n=482$, mid provisioning: $n=722$ prey items). Single prey items brought back to the colony were almost exclusively fish, with only one cephalopod species identified during the 2018 breeding season (Table 1).
Table 1 Numbers and proportions of prey species photographed in the bills of greater crested terns returning to the colony at Montague Island in 2018 according to the breeding stage of the terns. A total of
2469 prey items were identifiable to species or family level of which 1265 prey were identified during incubation (adult diet) and 1204 during provisioning stages (chick diet)

\begin{tabular}{|c|c|c|c|c|c|c|c|c|}
\hline \multirow[t]{2}{*}{ Common name } & \multirow[t]{2}{*}{ Scientific name } & \multirow[t]{2}{*}{ Family } & \multicolumn{2}{|c|}{ Adult } & \multicolumn{2}{|l|}{ Chick } & \multicolumn{2}{|l|}{ Total } \\
\hline & & & $N$ & $\%$ & $N$ & $\%$ & $N$ & $\%$ \\
\hline Australian anchovy & Engraulis australis & Engraulidae & 974 & 77.0 & 1112 & 92.4 & 2086 & 84.5 \\
\hline Barracouta & Thyrsites atun & Gempylidae & 114 & 9.0 & 6 & 0.5 & 120 & 4.9 \\
\hline Trevally spp. & Indet. spp. & Centralophidae & 76 & 6.0 & 10 & 0.8 & 86 & 3.5 \\
\hline Goatfish spp. & Indet. spp. & Mullidae & 7 & 0.6 & 40 & 3.3 & 47 & 1.9 \\
\hline Bluebottle fish & Nomeus gronovii & Nomeidae & 12 & 0.9 & 22 & 1.8 & 34 & 1.4 \\
\hline Eastern sea garfish & Hyporhamphus australis & Hemiramphidae & 20 & 1.6 & 7 & 0.6 & 27 & 1.1 \\
\hline Southern calamari squid & Sepioteuthis australis & Loliginidae & 27 & 2.1 & 1 & 0.1 & 28 & 1.1 \\
\hline Redbait & Emmelichthys nitidus & Emmelichthyidae & 22 & 1.7 & 0 & 0.0 & 22 & 0.9 \\
\hline King gar & Scomberesox saurus & Scomberesocidae & 7 & 0.6 & 1 & 0.1 & 8 & 0.3 \\
\hline Silver sweep & Scorpis lineolata & Scorpididae & 5 & 0.4 & 2 & 0.2 & 8 & 0.3 \\
\hline Pilotfish & Naucrates ductor & Carangidae & 1 & 0.1 & 1 & 0.1 & 2 & 0.1 \\
\hline Flying fish spp. & Indet. spp. & Exocoetidae & 0 & 0.0 & 1 & 0.1 & 1 & 0.04 \\
\hline
\end{tabular}

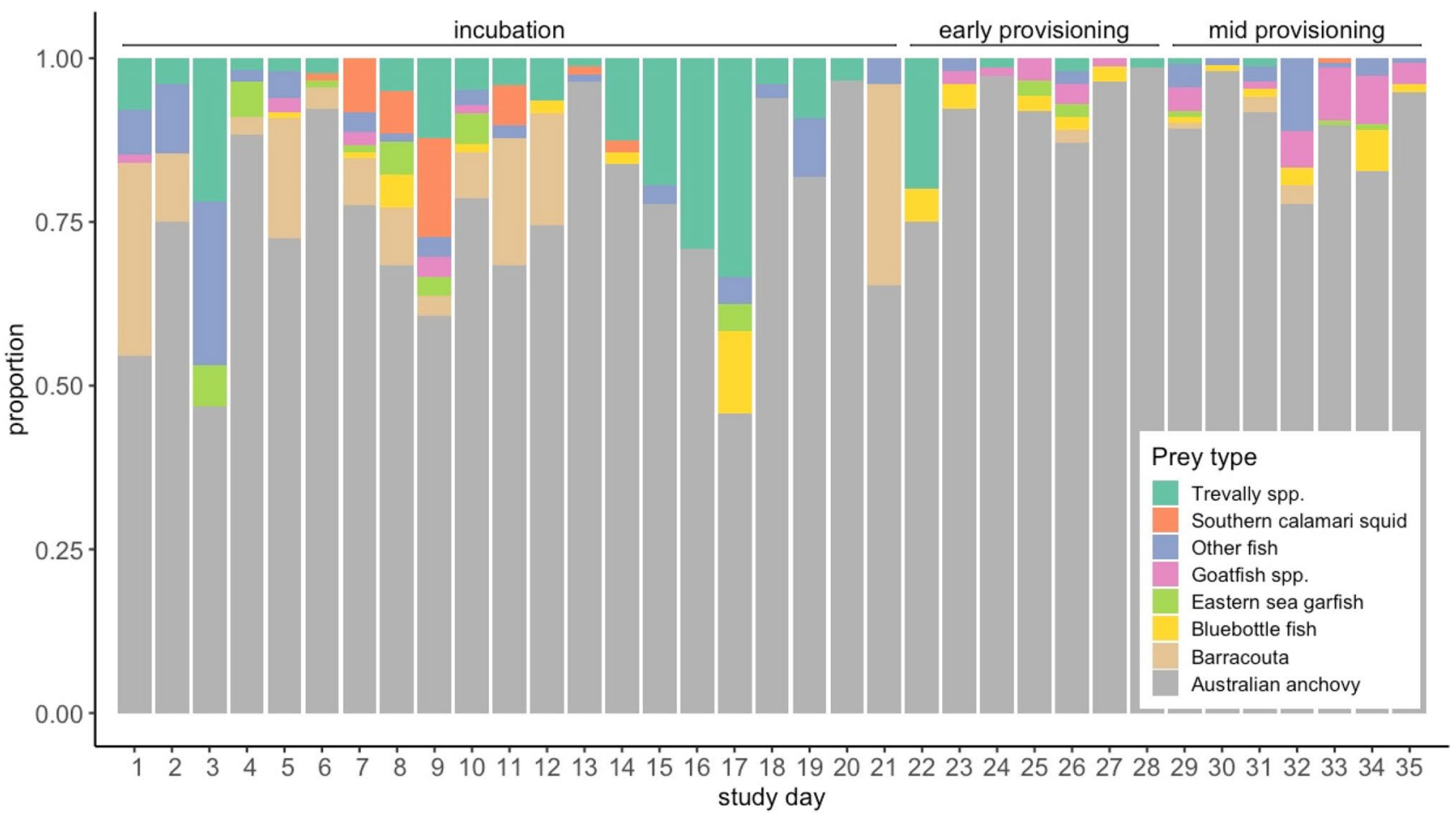

Fig. 2 Daily variation in greater crested tern diet across study period ( $n=35$ days) and breeding stages: incubation (study day 1-21), early provisioning (study day 22-28), mid provisioning (study day 29-35). Depicted are the seven main prey species (Australian anchovy, bar- racouta, bluebottle fish, eastern sea garfish, goatfish spp., southern calamari squid, trevally spp.) and other fish (prey items making up a total abundance of $<1 \%$ over the breeding season) returned to the breeding colony 
Fig. 3 Non-metric multidimensional scaling plot (NMDS) showing differences in prey composition across three breeding stages (incubation, early provisioning, mid provisioning) by greater crested terns at Montague Island. Sample points represent the daily mean contributions of each of the seven main prey species (Australian anchovy, barracouta, bluebottle fish, eastern sea garfish, goatfish spp., southern calamari squid, trevally spp.) and other fish (OF, prey items making up a total abundance of $<1 \%$ over the breeding season) returned to the breeding colony. The three colours represent each different breeding stage, while ellipses highlight the centre of gravity and inertia of each breeding stage

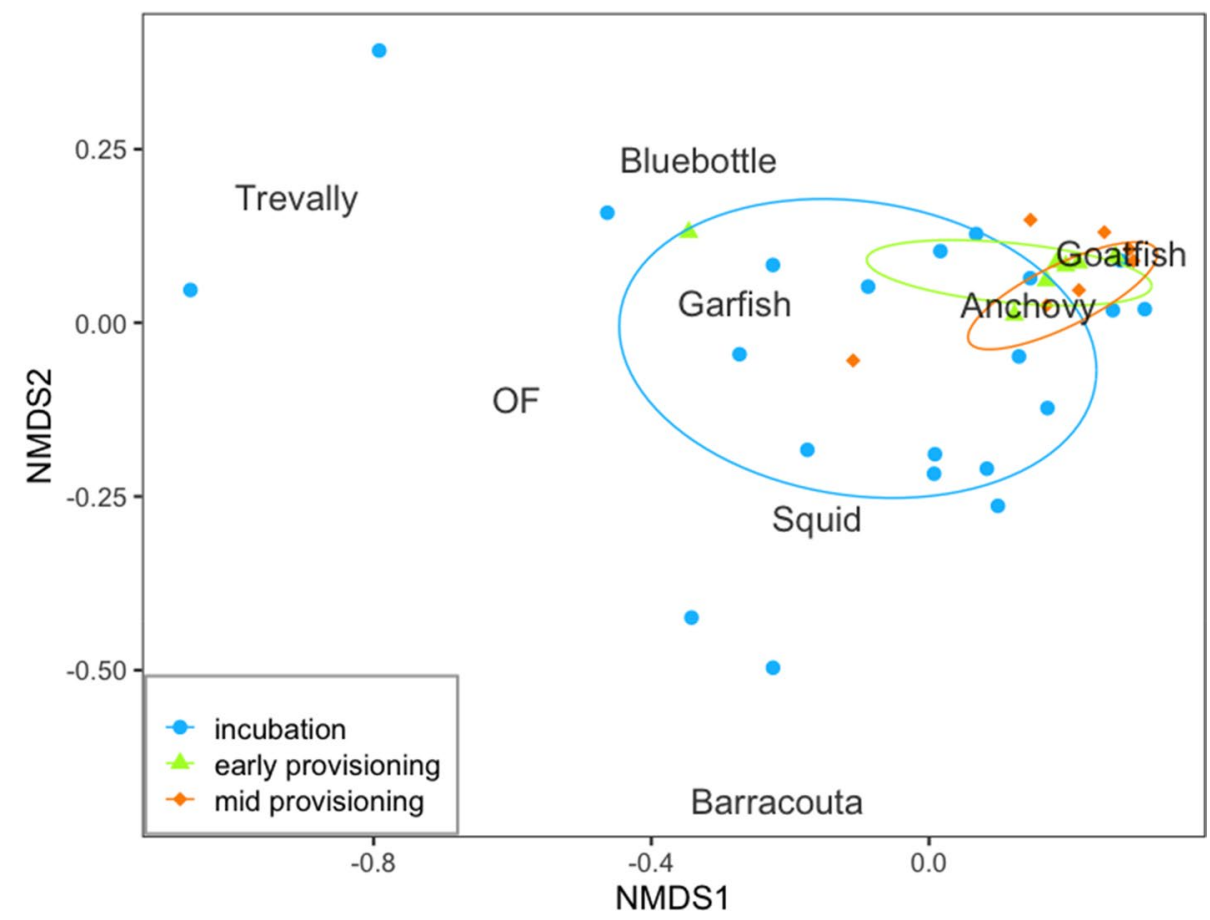

Seven main prey types were identified of which Australian anchovy was the dominant species during all breeding stages $(84.5 \%$, Table 1$)$. The diet was more diverse during incubation compared to early provisioning (Figs. 2, 3). During incubation, in addition to anchovy, other prey such as barracouta, trevallies and southern calamari squid were frequently brought back to the colony but their abundance decreased once chicks hatched. In contrast, species such as bluebottle fish and goatfish occurred more frequently in the diet of crested terns provisioning chicks, compared to incubation (Table 1; Figs. 2, 3).

There was a significant difference in the proportion of anchovy returned to the colony between the incubation (adult diet) and chick provisioning periods ( $\chi^{2}$ test, $X=13.72, p<0.01$ ), with terns selecting less anchovy when bringing prey back to the adult partner. Specifically, the mean proportion of anchovy in the diet increased significantly from $77.0 \%$ (incubation) to $92.9 \%$ once chicks hatched (early provisioning). During mid provisioning, the proportion of anchovy was $91.9 \%$. This was significantly higher than during incubation, but not significantly different from early provisioning (Fig. 4a). Statistical results for differences in anchovy proportions between breeding stages are summarised in Table 2.

\section{Anchovy size}

423 images $(\sim 20 \%)$ out of 2086 prey items identified as anchovy were used to measure anchovy size. The standard length (SL) of anchovies brought back to the colony ranged from 19.7 to $143.4 \mathrm{~mm}$. Anchovies were largest during incubation when birds were bringing fish back for their partner (mean $\pm \mathrm{SD}=91.1 \pm 14.9 \mathrm{~mm}, n=193)$. There was a significant decrease in anchovy SL to a mean size of $71.8 \pm 11.0 \mathrm{~mm}, n=84$ during early provisioning (Fig. $4 \mathrm{~b}$ ). Anchovy SL increased slightly to $79.6 \pm 11.9 \mathrm{~mm}, n=146$ during mid provisioning which was significantly smaller than incubation, but not significantly different from the early provisioning stage (Table 3 ).

\section{Diet composition in relation to environmental factors}

The GAMM revealed that the proportion of anchovy in the diet of greater crested terns increased with warmer SSTs, with the rate of increase slowing slightly at SSTs above $17.5{ }^{\circ} \mathrm{C}$ (Fig. 5). Neither wind speed nor wave height had a significant influence on the proportion of anchovy returned to the breeding colony (Table 4).

\section{Discussion}

This study quantified the type and size of prey exploited by a marine predator, the greater crested tern, during the 2018 breeding season at Montague Island, Australia. Using photographic sampling of prey items brought back to the colony, diet data were related to breeding stage and variation in local environmental conditions. 
Fig. 4 a The proportion of anchovy and $\mathbf{b}$ anchovy standard length $(\mathrm{mm})$ in the diet of greater crested terns across three breeding stages (incubation, early provisioning, mid provisioning) at Montague Island in the 2018 breeding season. Box plots show the median and first and third quartile; whiskers extend to the 1.5 times the interquartile range. Black dots represent outliers.

Significance levels are depicted as $* p \leq 0.05$ and $* * p<0.01$
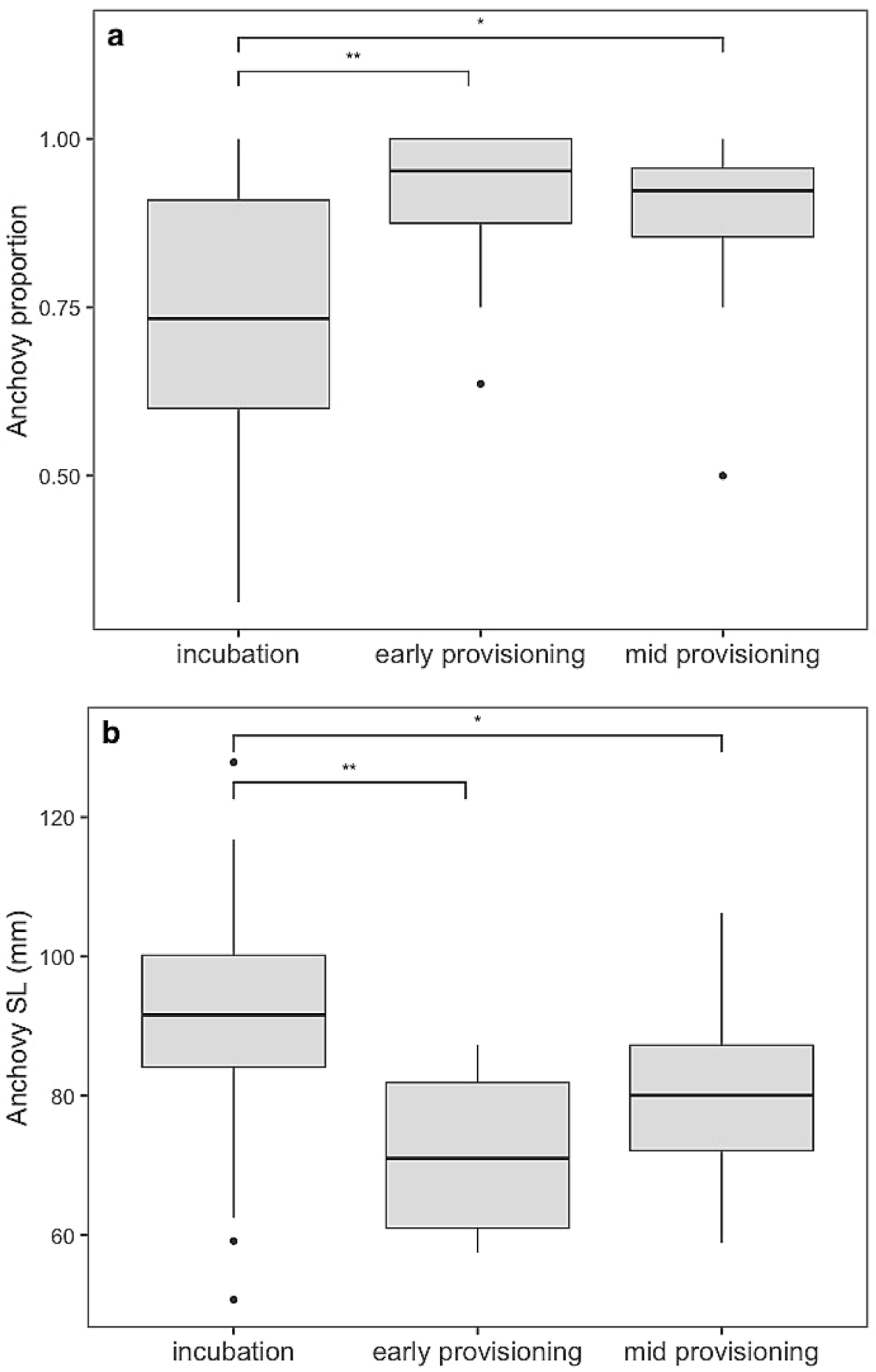

Table 2 Relationship between breeding stage (incubation, early provisioning, mid provisioning) on the proportion of anchovy in the diet of greater crested terns in 2018. Mean (\%) anchovy proportion and Tukey test adjusted $p$ values from comparisons across breeding stages are presented

\section{Dependent variable Breeding stage Mean (\%) Estimate Std. error $z$ ratio $p$ value}

\begin{tabular}{llllllll} 
& \multicolumn{1}{c}{ Early prov } & \multicolumn{4}{c}{ Mid prov } \\
\hline Anchovy proportion & Incubation & 77.0 & -0.957 & 0.277 & -3.459 & $<\mathbf{0 . 0 1}$ & $\mathbf{0 . 0 4 6}$ \\
& Early prov & 92.9 & -0.648 & 0.268 & -2.414 & - & 0.62 \\
& Mid prov & 91.9 & 0.309 & 0.332 & 0.931 & - & - \\
\hline
\end{tabular}

Bold values represent significant results 
Table 3 Relationship between breeding stage on anchovy standard length $(\mathrm{mm})$ estimated from photo-samples $(n=423)$ of greater crested terns in 2018. Mean (SD) and Tukey test adjusted $p$ values

\begin{tabular}{|c|c|c|c|c|c|c|c|}
\hline \multirow[t]{2}{*}{ Dependent variable } & \multirow[t]{2}{*}{ Breeding stage } & \multirow[t]{2}{*}{ Mean (SD) mm } & \multirow[t]{2}{*}{ Estimate } & \multirow[t]{2}{*}{ Std. error } & \multirow[t]{2}{*}{$\mathrm{z}$ ratio } & \multicolumn{2}{|l|}{$p$ value } \\
\hline & & & & & & Early prov & Mid prov \\
\hline \multirow[t]{3}{*}{ Anchovy SL } & Incubation & $91.1(14.9)$ & 18.24 & 5.18 & 3.52 & $<0.01$ & 0.05 \\
\hline & Early prov & $71.8(11.0)$ & 12.07 & 4.93 & 2.45 & - & 0.58 \\
\hline & Mid prov & 79.6 (11.9) & -6.17 & 6.15 & -1.00 & - & - \\
\hline
\end{tabular}

Bold values represent significant results

Fig. 5 Partial effect of the environmental covariate SST on the proportion of anchovy returned to the greater crested tern breeding colony at Montague Island, Australia, in 2018. $s(x, y)$ is the smoothing term, with $x$ the explanatory variable and $y$ the estimated degrees of freedom of the smoothing term. Pointwise 95\% confidence intervals are shown for each model fit from comparisons across three breeding stages, incubation $(n=193)$, early provisioning $(n=84)$, and mid provisioning $(n=146)$ are presented

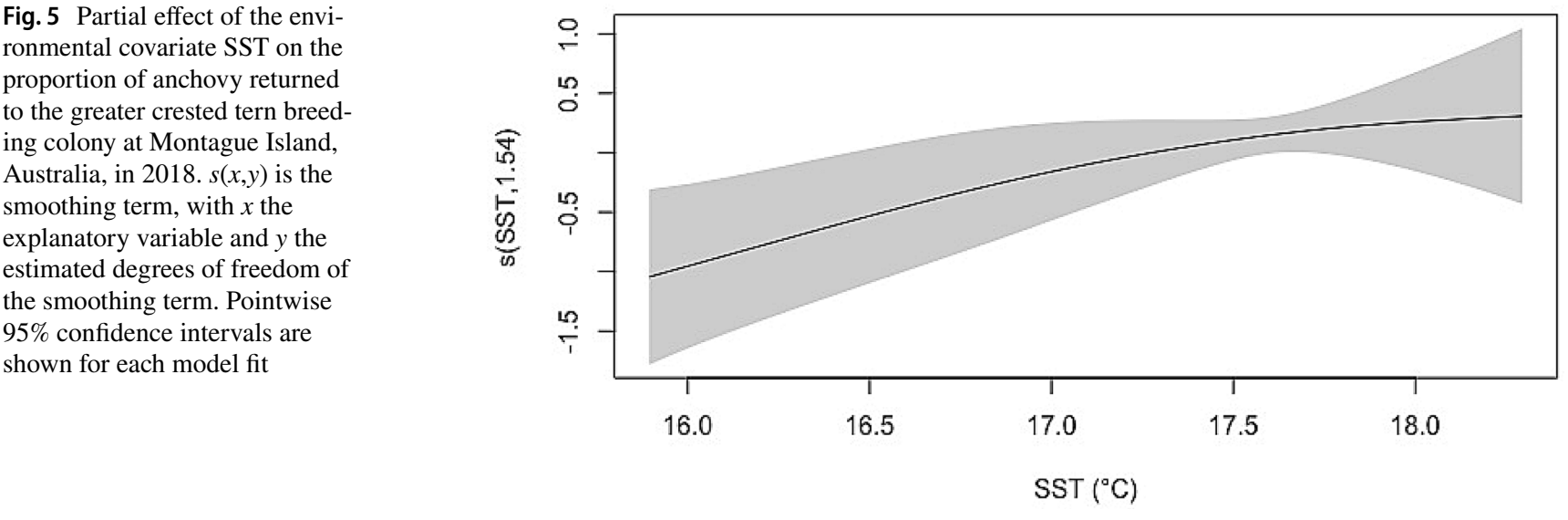

Table 4 Relationship between environmental variables (SST, wave height, wind speed) on the proportion of anchovy in the diet of greater crested terns using generalised additive mixed models (GAMMs). GAMM results include breeding stage as fixed effect.

Shown are the estimated degrees of freedom (edf), $\chi^{2}$ and $p$ values for each environmental parameter, as well as the percent deviance explained as measure of model performance

\begin{tabular}{lllrrr}
\hline Dependent variable & $\begin{array}{l}\text { Environmental variable } \\
\text { (smooth term) }\end{array}$ & $\begin{array}{l}\text { Estimated degrees of } \\
\text { freedom }\end{array}$ & $\chi^{2}$ & $\begin{array}{l}p \text { value } \\
\text { explained }\end{array}$ \\
\hline Anchovy proportion & SST & 1.54 & 10.57 & $\mathbf{0 . 0 2}$ & $33 \%$ \\
& Wave height & 1.75 & 1.68 & 0.41 & $36.2 \%$ \\
& Wind speed & 2.22 & 3.67 & 0.22 & $44.7 \%$ \\
\hline
\end{tabular}

Bold values represent significant results

\section{Prey composition and size}

Small surface-schooling clupeids, dominated by the Australian anchovy (Engraulis australis), were the most abundant prey type returned to the colony during the breeding season, consistent with findings on diet composition of crested terns in other geographic locations and oceanographic systems: in South Africa, anchovy (E. spp.) were found to be the most abundant prey items of crested terns at multiple colonies (Walter et al. 1987; Gaglio et al. 2018). Elsewhere in Australia, the diet composition of juvenile crested terns in Victoria was dominated by two prey species, Australian anchovy and Jack mackerel (Trachurus declivis) (Chiaradia et al. 2002). Crested terns in South Australia were more generalist predators feeding predominantly on Australian anchovy, sardine (Sardinops sagax) and blue sprat (Spratelloides robustus) (McLeay et al. 2009), highlighting that variation in the distribution of prey species and environmental factors that affect foraging are likely to influence diet composition at different sites. Barracouta was the second most abundant prey in the diet in our study and is also an important prey species of crested terns in both Victoria and South Australia (Chiaradia et al. 2002; McLeay et al. 2009). Barracouta in southern New South Wales spawn in late winter (July-August; Bray and Schultz 2020), which may explain the occurrence of smaller (juvenile) barracouta in the diet of adult crested terns at the onset of the spring breeding season. Their absence later in the season may be because they grow 
too large for chicks to swallow. Some demersal fish species were also found in the diet, including bluebottle fish. While demersal as adults, bluebottle fish are pelagic as juveniles and occur near the sea surface where they were presumably captured by terns (Bray 2020). Southern calamari squid occurred in small numbers and are also demersal, in shallow $(<10 \mathrm{~m})$ inshore waters, but are occasionally also found near the surface (Norman and Reid, 2000).

The proportion and size of anchovy returned to the breeding colony varied between incubation and chick provisioning, with chicks consuming a significantly higher proportion of anchovy than adults during early and mid provisioning. Anchovies returned to the breeding colony were smallest during early chick rearing. Hatchlings are limited in the size of prey they can swallow and this means parents need to select smaller prey at sea. As chicks grow, parents may need to adjust for their increasing energetic requirements to maximise growth rates. The observed increase in anchovy size with chick age supports previous findings that there is size-selective predation by adult terns through the breeding season in response to changing energetic demands of nestlings (Hulsman et al. 1989; Shealer 1998; McLeay et al. 2009; Gaglio et al. 2018). However, while these findings suggest active prey selection by adult terns in response to breeding stage, the influence of spatiotemporal availability of prey on diet composition should not be discounted.

\section{Environmental factors}

Environmental factors, such as temperature, drive the distribution and abundance of schooling fish, and thus the availability of prey to upper trophic levels in the ocean (Bertrand et al. 2008). The East Australian Current (EAC) transports warm and nutrient-depleted water southward along the New South Wales coastline (Suthers et al. 2011). This highly variable and dynamic system has intensified over recent decades (Phillips et al. 2020), with local SSTs off southeast Australia rising at a rate that is 3-4 times greater than the global average (Wu et al. 2012), and the area around Montague Island being a particular hotspot of warming within this region (Malan et al. 2021). The flow-on effects of these EAC dynamics include shifts in the distribution of pelagic fishes (Hobday et al. 2011; Champion et al. 2021), phytoplankton (Thompson et al. 2009), and larval recruitment (Cetina-Heredia et al. 2015).

In this study, SST was positively correlated with the proportion of anchovy returned to the breeding colony. The relationship between the spatial distribution of small pelagic fish stocks and environmental factors (e.g. temperature) have been reported in marine ecosystems globally (Peck et al. 2021), such as in the Patagonian stock of Argentinian anchovy, E. anchoita (Hansen et al. 2001). In accordance with our findings, greater crested terns in South Australia, which mainly prey on clupeid fishes during chick provisioning stages, typically foraged over warmer waters $\left(18-21^{\circ} \mathrm{C}\right)$ that are shallow and are associated with high levels of chlorophyll $a$ (McLeay et al. 2010). An earlier study in South Australia found that anchovy spawning was triggered by higher SSTs in spring (Kent et al. 2013) and larvae were more abundant in shelf waters with SSTs $<20^{\circ} \mathrm{C}$ near upwelling zones (Dimmlich et al. 2004). Ultimately, the impact of EAC dynamics and ocean warming on the foraging behaviour and breeding phenology of marine top predators, like greater crested terns, in southeast Australia may accelerate under future climate change (Phillips et al. 2020), making this seabird population an interesting study system and a potential future indicator of ecosystem change in response to ocean warming.

In additional previous research undertaken at Montague Island, Carroll et al (2016) concluded that reduced prey capture of forage fish by little penguins (Eudyptula minor) associated with anomalously cool SSTs might reflect a period early in the breeding season when water temperature had not been warm enough to facilitate phytoplankton growth, resulting in a lower local abundance of planktivorous fish. Likewise, SST $>21{ }^{\circ} \mathrm{C}$ impaired prey capture success at the end of the penguin's breeding season, related to a stronger influence of the warm EAC at this time (Phillips et al. 2020). Montague Island penguins have been shown to match the distribution of schooling forage fish like anchovy around the island when foraging, indicating that their prey capture success reflects local changes in prey availability that might be important for other sympatric predators such as greater crested terns (Carroll et al. 2017). Range-restricted species, such as breeding seabirds, may thus be particularly sensitive to the local availability of key prey species at crucial times in their breeding cycle (Crawford et al. 2006).

Breeding phenology in birds is likely timed to coincide with periods of peak resource availability. The prevalence of anchovy in the diet increased with SST in this study, and SST was seasonally elevated during chick provisioning stages (see online resources Fig. 1). It is possible that the timing of breeding is linked to elevated levels of production, indicated by greater proportions of energy-rich prey (e.g. anchovy) in the diet during chick provisioning. In support of the latter, anchovy abundance and availability to Peruvian seabirds increased during the period of chick provisioning with a peak around the time of fledging, suggesting breeding timing is adjusted to optimal environmental conditions facilitating chick or fledgling survival (Passuni et al. 2016). Importantly, the extent to which a dietary shift in this study can truly be linked to prey availability and its influence by environmental covariates such as SST would require additional research on estimates of fish stock composition and abundance around Montague Island by, for example, local 
fishery assessments or acoustic surveys (e.g. Green et al. 2015; Carroll et al. 2017; Thayne et al. 2019). Undertaking this research would allow greater insight into the mechanisms underpinning variability in diet composition in marine predators in southeast Australia, and give further insight into whether the diet of breeding crested terns can provide a useful indicator of changing conditions in the coastal pelagic ecosystem in southeast Australia.

\section{Conclusion}

This study found that the diet of greater crested terns off southeast Australia was dominated by a single, energy-rich small pelagic fish (Australian anchovy). The proportion and size of this key prey species within the diet of greater crested terns was found to vary with sea surface temperature and breeding stage, respectively. This reflects a combination of selective foraging behaviour of the terns to meet the changing energetic demands of partners and chicks, and spatiotemporal changes in the availability of their prey. Further studies should preferably examine seabird diet composition and fitness parameters (e.g. chick body condition and survival) simultaneously, as well as the spatial and temporal availability of prey in the terns' foraging areas to disentangle these effects and to make inferences for management and predictions of anthropogenic impacts on this species. By showing a strong selectivity for only one energy-rich species of schooling fish, we suggest that greater crested terns may be an informative bioindicator of changes in the pelagic ecosystem, as has been suggested for other specialised seabird species (Courtens et al. 2017; Hazen et al. 2019).

Supplementary Information The online version contains supplementary material available at https://doi.org/10.1007/s00227-021-03947-3.

Acknowledgements KQ received the opportunity to visit Australia and conduct the study through a graduate student exchange program between Georg-August-University Göttingen and Macquarie University. We thank Lachlan Phillips for his assistance in the field and the NSW National Parks and Wildlife Service for their ongoing commitment to this project and for logistical support on Montague Island. We also thank four anonymous reviewers for their comments on this manuscript.

Author contributions RH, GC, KQ conceived the ideas and designed the study; KQ collected the data; KQ and CC processed photographs and collated data; KQ and GC analysed the data and led the writing of the manuscript. All authors contributed critically to the drafts and gave final approval for publication.

Funding Open Access funding enabled and organized by Projekt DEAL. This project was funded by an Australian Research Council Linkage Grant to Ian Jonsen, GC, RH and others (LP160100162).
Data availability The datasets generated and/or analysed during the current study are available from the corresponding author on reasonable request.

\section{Declarations}

Conflict of interest The authors declare that they do not have conflicts of interest or competing interests.

Ethics approval This project was conducted under NSW NPWS Scientific Licence SL170064 and Macquarie University Animal Research Authority 2014-057. All applicable international, national, and institutional guidelines for the care and use of animals were followed.

Open Access This article is licensed under a Creative Commons Attribution 4.0 International License, which permits use, sharing, adaptation, distribution and reproduction in any medium or format, as long as you give appropriate credit to the original author(s) and the source, provide a link to the Creative Commons licence, and indicate if changes were made. The images or other third party material in this article are included in the article's Creative Commons licence, unless indicated otherwise in a credit line to the material. If material is not included in the article's Creative Commons licence and your intended use is not permitted by statutory regulation or exceeds the permitted use, you will need to obtain permission directly from the copyright holder. To view a copy of this licence, visit http://creativecommons.org/licenses/by/4.0/.

\section{References}

Batchelor AL, Ross GJB (1984) The diet and implications of dietary change of Cape gannets on Bird Island, Algoa Bay. Ostrich $55: 45-63$

Bates D, Mächler M, Bolker B, Walker S (2014) Fitting linear mixedeffects models using lme4. J Stat Softw 67:1-48

Bertrand A, Gerlotto F, Bertrand S et al (2008) Schooling behaviour and environmental forcing in relation to anchoveta distribution: An analysis across multiple spatial scales. Prog Oceanogr 79:264-277

Borcard D, Gillet F, Legendre P (2018) Numerical ecology with R. Springer, New York

Bray DJ, Schultz S (2020) Thyrsites atun in fisheries of Australia. http://136.154.202.208/home/species/711. Accessed 01 Aug 2020

Bray DJ (2020) Nomeus gronovii in fishes of Australia. http://136.154. 202.208/home/species/2927. Accessed 02 Aug 2020

Brooks ME, Kristensen K, van Benthem KJ et al (2017) glmmTMB balances speed and flexibility among packages for zero-inflated generalized linear mixed modeling. R J 9:378-400

Cairns DK (1988) Seabirds as indicators of marine food supplies. Biol Oceanogr 5:261-271

Carroll G, Everett JD, Harcourt R et al (2016) High sea surface temperatures driven by a strengthening current reduce foraging success by penguins. Sci Rep 6:1-13

Carroll G, Cox M, Harcourt R et al (2017) Hierarchical influences of prey distribution on patterns of prey capture by a marine predator. Funct Ecol 31:1750-1760

Cetina-Heredia P, Roughan M, Sebille E et al (2015) Strengthened currents override the effect of warming on lobster larval dispersal and survival. Glob Change Biol 21:4377-4386 
Champion C, Brodie S, Coleman MA (2021) Climate-driven range shifts are rapid yet variable among recreationally important coastal-pelagic fishes. Front Mar Sci 8:156

Chiaradia A, Dann P, Jessop R et al (2002) The diet of crested tern (Sterna bergii) chicks on Phillip Island, Victoria, Australia. Emu 102:367-371

Courtens W, Verstraete H, Vanermen N, Van de walle Stienen MEWM (2017) Faecal samples reveal the diet of breeding adult Sandwich terns Thalasseus sandvicensis in Belgium and the southern part of the Netherlands. J Sea Res 127:182-193

Crawford RJM, Barham PJ, Underhill LG et al (2006) The influence of food availability on breeding success of African penguins Sphensicus demersus at Robben Island, South Africa. Biol Conserv 132:119-125

Dimmlich WF, Breed WG, Geddes M, Ward TM (2004) Relative importance of gulf and shelf waters for spawning and recruitment of Australian anchovy, Engraulis australis, in South Australia. Fish Oceanogr 13:310-323

Durant JM, Anker-Nilssen T, Stenseth NC (2003) Trophic interactions under climate fluctuations: the Atlantic puffin as an example. Proc R Soc B 270:1461-1466

Elliott KH, Bull RD, Gaston AJ, Davoren GK (2009) Underwater and above-water search patterns of an Arctic seabird: reduced searching at small spatiotemporal scales. Behav Ecol Sociobiol 63:1773-1785

Elliott KH, Chivers LS, Bessey L et al (2014) Windscapes shape seabird instantaneous energy costs but adult behavior buffers impact on offspring. Mov Ecol 2:17

Gaglio D, Cook TR, Connan M, Ryan PG, Sherley RB (2017) Dietary studies in birds: testing a non-invasive method using digital photography in seabirds. Methods Ecol Evol 8:214-222

Gaglio D, Cook TR, McInnes A, Sherley RB, Ryan PG (2018) Foraging plasticity in seabirds: a non-invasive study of the diet of greater crested terns breeding in the Benguela region. PLoS ONE 13:e0190444

Green DB, Klages NT, Crawford RJ et al (2015) Dietary change in Cape gannets reflects distributional and demographic shifts in two South African commercial fish stocks. ICES J Mar Sci 72:771-781

Hansen JE, Martos P, Madirolas A (2001) Relationship between spatial distribution of the Patagonian stock of Argentine anchovy, Engraulis anchoita, and sea temperatures during late spring to early summer. Fish Oceanogr 10:193-206

Harwood LA, Smith TG, George JC et al (2015) Change in the Beaufort Sea ecosystem: diverging trends in body condition and/or production in five marine vertebrate species. Prog Oceanogr 136:263-273

Hazen EL, Abrahms B, Brodie S et al (2019) Marine top predators as climate and ecosystem sentinels. Front Ecol Environ 17:565-574

Hobday DK (1992) Abundance and distribution of pilchard and Australian anchovy as prey species for the little penguin Eudyptula minor at Phillip Island, Victoria. Emu 91:342-354

Hobday AJ, Pecl GT (2014) Identification of global marine hotspots: sentinels for change and vanguards for adaptation action. Rev Fish Biol Fisher 24:415-425

Hobday A, Young J, Moeseneder C et al (2011) Defining dynamic pelagic habitats in oceanic waters off eastern Australia. Deep Sea Res Part II 58:734-745

Hoedt FE, Dimmlich WF (1994) Diet of subadult Australian salmon, Arripis truttaceus, in Western Port, Victoria. Aust J Mar Freshw Res 45:617-623
Howells RJ, Burthe SJ, Green JA et al (2017) From days to decades: short-and long-term variation in environmental conditions affect offspring diet composition of a marine top predator. Mar Ecol Prog Ser 583:227-242

Hulsman K, Langham NPE, Bluhdorn D (1989) Factors affecting the diet of crested terns, Sterna bergii. Wildl Res 16:475-489

Kent J, Jenkins G, Acevedo S (2013) Temporal and spatial patterns in ichthyoplankton assemblages in bay and open coastal environments. J Fish Biol 82:408-429

Kogure Y, Sato K, Watanuki Y et al (2016) European shags optimize their flight behavior according to wind conditions. J Exp Biol 219:311-318

Lenth R (2020) emmeans: estimated marginal means, aka least-squares means. $\mathrm{R}$ package version 1.4.6

Lorentsen SH, Anker-Nilssen T, Erikstad KE (2018) Seabirds as guides for fisheries management: European shag Phalacrocorax aristotelis diet as indicator of saithe Pollachius virens recruitment. Mar Ecol Prog Ser 586:193-201

Malan N, Roughan M, Kerry C (2021) The rate of coastal temperature rise adjacent to a warming western boundary current is nonuniform with latitude. Geophys Res Lett. https://doi.org/10.1029/ 2020GL090751

McLeay LJ, Page B, Goldsworthy SD et al (2009) Size matters: variation in the diet of chick and adult crested terns. Mar Biol 156:1765-1780

McLeay LJ, Page B, Goldsworthy SD et al (2010) Foraging behaviour and habitat use of a short-ranging seabird, the crested tern. Mar Ecol Prog Ser 411:271-283

Norman M, Reid A (2000) A guide to squid, cuttlefish and octopuses of Australasia. CSIRO Publishing, Victoria

O'Hara D (2016) Increased spatial resource partitioning among a multispecies seabird colony in a lower productivity year. Master thesis, Macquarie University, Sydney

Oksanen J (2011) Multivariate analysis of ecological communities in $\mathrm{R}$ : vegan tutorial. $\mathrm{R}$ package version 1, pp 1-43

Orians GH, Pearson NE (1979) On the theory of central place foraging. In: Horn DJ, Mitchell RD, Stairs GR (eds) Analysis of ecological systems. Ohio State University Press, Columbus, pp 157-177

Parsons M, Mitchell I, Butler A et al (2008) Seabirds as indicators of the marine environment. ICES J Mar Sci 65:1520-1526

Passuni G, Barbraud C, Chaigneau A et al (2016) Seasonality in marine ecosystems: Peruvian seabirds, anchovy, and oceanographic conditions. Ecology 97:182-193

Peck MA, Alheit J, Bertrand A et al (2021) Small pelagic fish in the new millennium: a bottom-up view of global research effort. Prog Oceanogr 191:102494

Phillips LR, Carroll G, Jonsen I et al (2020) A water mass classification approach to tracking variability in the East Australian Current. Front Mar Sci 7:365

Pichegru L, Ryan PG, van der Lingen CD et al (2007) Foraging behaviour and energetics of Cape gannets Morus capensis feeding on live prey and fishery discards in the Benguela upwelling system. Mar Ecol Prog Ser 350:127-136

R Core Team (2017) R: a language and environment for statistical computing. R Foundation for Statistical Computing, Vienna, Austria

Shealer DA (1998) Size-selective predation by a specialist forager, the Roseate tern. Auk 115:519-525

Smithson M, Verkuilen J (2006) A better lemon squeezer? Maximumlikelihood regression with beta-distributed dependent variables. Psychol Methods 11:54 
Stienen EW, Van Beers PW, Brenninkmeijer A et al (2000) Reflections of a specialist: patterns in food provisioning and foraging conditions in Sandwich Terns Sterna sandvicensis. Ardea 88:33-49

Suryan RM, Irons DB, Kaufman M et al (2002) Short-term fluctuations in forage fish availability and the effect on prey selection and brood-rearing in the black-legged kittiwake Rissa tridactyla. Mar Ecol Prog Ser 236:273-287

Suthers IM, Young JW, Baird ME et al (2011) The strengthening East Australian Current, its eddies and biological effects-an introduction and overview. Deep Sea Res Part II 58:538-546

Thayne MW, Santora JA, Saenz B et al (2019) Combining seabird diet, acoustics and ecosystem surveys to assess temporal variability and occurrence of forage fish. J Mar Syst 190:1-14

Thompson P, Baird ME, Ingleton T (2009) Long-term changes in temperate Australian coastal waters: implications for phytoplankton. Mar Ecol Prog Ser 394:1-19

Walter CB, Cooper J, Sulter W (1987) Diet of swift tern chicks in the Saldanha Bay Region, South Africa. Ostrich 58:49-53

Watson MJ (2012) Effects of parasites on the crested tern Thalasseus bergii. Charles Sturt University, Bathurst
White TCR (2008) The role of food, weather and climate in limiting the abundance of animals. Biol Rev 83:227-248

Whitehead PJP, Nelson GJ, Wongratana T (1988) Clupeoid fishes of the world (Suborder Clupeoidei). An annotated and illustrated catalogue of the herrings, sardines, pilchards, sprats, shads, anchovies and wolf-herrings. FAO Fish Synop 125:305-579

Wood SN (2006) Generalized additive models: an introduction with R. Chapman and Hall, New York

Wu L, Cai W, Zhang L et al (2012) Enhanced warming over the global subtropical western boundary currents. Nat Clim Change 2:161-166

Zuur A, Ieno EN, Walker N, Saveliev AA, Smith GM (2009) Mixed effects models and extensions in ecology with R. Springer Science $\&$ Business Media, New York

Publisher's Note Springer Nature remains neutral with regard to jurisdictional claims in published maps and institutional affiliations. 